\title{
invitedreview/cmearticle
}

\section{A new age in the genetics of deafness}

\author{
Heidi L. Rehm, MMSc ${ }^{l}$ and Cynthia C. Morton, $P h D^{2}$
}

Over the last several years, an understanding of the genetics of hearing and deafness has grown exponentially. This progress has been fueled by fast-paced developments in gene mapping and discovery, leading to the recent cloning and characterization of many genes critical in the biology of hearing. Among the most significant advances, especially from a clinical perspective, is the discovery that up to $50 \%$ of nonsyndromic recessive deafness is caused by mutations in the GJB2 gene, which encodes the connexin 26 protein $(\mathrm{C} \times 26))^{1.2}$ The clinical use of screening for mutations in $\mathrm{Cx} 26$ and other genes involved in hearing impairment is still a new concept and not widely available. However, the eventual availability of an array of genetic tests is likely to have a major impact on the medical decisions made by hearing-impaired patients, their families, and their physicians. It is likely that information from these tests will simplify the diagnoses, prognoses, and treatment decisions offered by the physician. Furthermore, the use of genetic testing will assist individuals in understanding the molecular basis and heritability of their hearing loss.

This review presents an overview of current topics relating to the genetics of deafness including the different forms of deafness and their prevalence. The basic process of hearing and the functions of the various genes that have been cloned for nonsyndromic deafness will be described. In addition, nongenetic causes of deafness will be reviewed, because they are important in the differential diagnosis when considering a genetic basis for a patient's deafness. The implications of universal newborn hearing screening and its recent implementation in many states will also be addressed. Furthermore, important factors involved in the clinical diagnosis of the etiology of deafness, as well as factors relating to intervention and management of children with hearing impairment, will be discussed. Finally, this review will consider genetic counseling for deafness and some of the issues important to the Deaf community. Although the topics presented here have not seen their last assessment, this review will explore the basics upon which new knowledge can be gradually added.

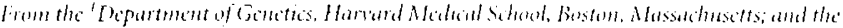

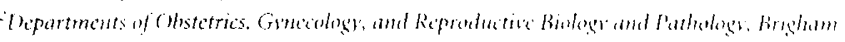

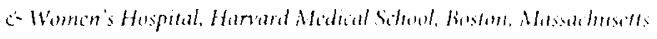

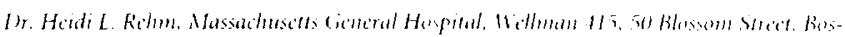
[On, MAOSII4

Kicioned: Septimler 27. 1999

Accipted: Siptimber 27. 1999.
}

\section{SYNDROMIC AND NONSYNDROMIC DEAFNESS}

The prevalence of severe to profound bilateral congenital hearing loss is estimated at 1 in 1000 births. ${ }^{3}$ When milder forms of permanent hearing impairment at birth are included, this estimate increases four-fold. Congenital deafness refers to deafness present at birth, though the cause of such hearing impairment may be genetic (hereditary) or environmental (acquired). Various studies estimate that approximately one-half of the cases of congenital deafness are due to genetic factors, ${ }^{3}$ and these factors can be further subdivided by mode of inheritance. Approximately $77 \%$ of cases of hereditary deafness are autosomal recessive, $22 \%$ are autosomal dominant, and $1 \%$ are $\mathrm{X}$-linked. ${ }^{+}$In addition, a small fraction of hereditary deafness $(<1 \%)$ represents those families with mitochondrial inheritance in which the trait is passed through the maternal lineage.

Aside from mode of inheritance, there are a number of other descriptions used to classify types of deafness. These include age of onset (prelingual vs. postlingual), severity (mild, moderate, severe, or profound, unilateral vs. bilateral), presence of other anomalies (nonsyndromic vs. syndromic), etiology (genetic vs. acquired), type of pathology (sensorineural, conductive, or mixed), and stability of the hearing loss (temporary vs. permanent, stable, progressive, or fluctuating). An important distinction exists between sensorineural deafness and conductive deafness. Conductive hearing loss typically results from problems associated with the external or middle ear, whereas sensorineural loss indicates dysfunction of the cochlea or auditory nerve. Although the type of pathology varies widely among the syndromic forms of deafness, with minor exception, nonsyndromic deafness is typically sensorineural. An additional consideration is whether the hearing loss is prelingual or postlingual. Even though hearing loss can develop at any age, this distinction is important because prelingual deafness often leads to difficulties with speech and language development.

Although the incidence of prelingual hearing loss is relatively high as compared with other childhood disorders, an even larger percentage of the population is affected by postlingual hearing impairment, with the majority of these cases being age-related hearing loss (presbycusis). In fact, it is estimated that hearing impairment affects one-half of the population in the United States by age $80 .{ }^{*}$ This emphasizes the finding that hearing loss is a major public health concern affecting a large segment of the general population.

Despite the observation that the majority of deaf and hearing-impaired individuals have no other symptoms, approxi- 
mately $30 \%$ of patients with prelingual deafness also have additional medical anomalies. ${ }^{3}$ More than 400 such syndromic forms of deafness have been characterized, with the most complete collection of these disorders found in Gorlin and colleagues' Hereditary Hearing Loss and Its Syndromes. ${ }^{3}$ Many of these syndromes are quite rare, and the responsible genes are unknown, yet the genes for the most common syndromes and a few for the rarer forms have been cloned in recent years. Those syndromes with higher prevalence are listed in Table 1 with their accompanying phenotype (not including deafness) and responsible protein.

The other $70 \%$ of hearing impairment cases fall into the category of nonsyndromic deafness. In these cases, the only clinical finding is hearing loss with the exception that some patients may have accompanying vestibular symptoms. Although deafness and vestibular dysfunction do not always occur together, the existence of many disorders involving both the auditory and vestibular systems reflects their close anatomic proximity and similar developmental origin and structure.

One of the difficulties in studying nonsyndromic deafness and discovering the underlying genetic causes has been the immense genetic heterogeneity that exists among nonsyndromic forms of deafness. Although subtle pathologic differences may allow clinical differentiation between certain subtypes of nonsyndromic deafness, there still exist a plethora of genes whose dysfunction can result in highly similar phenotypes. In fact, mapping efforts have located more than 66 independent loci for nonsyndromic deafness. ${ }^{5}$ Each locus is labeled "DFN" followed by "A" for dominant inheritance, "B" for recessive, or no additional letter for X-linked. A unique number is then added to the locus designation to indicate the sequential order in which the loci were mapped.
In general, autosomal recessive forms of deafness are prelingual and autosomal dominant ones tend to result in progressive, postlingual deafness. This likely reflects the fact that most recessive disorders represent a complete loss of a gene's function, whereas dominant disorders may mechanistically represent an interaction between the activity of the normal gene product and the activity of the mutant product.

The responsible gene has been identified at 15 of these nonsyndromic loci, marking great achievement in the last 3 years. Much of this success can be attributed to the vast contributions of the Human Genome Project in establishing high-density genetic maps and other tools for genetic analysis. However, there are still many genes to be identified. For a full summary of these loci, please refer to the frequently updated Hereditary Hearing Loss Homepage, which contains many tables summarizing the details of these nonsyndromic loci, as well as a wealth of other information related to research on the genetics of deafness. ${ }^{5}$ This web site represents an excellent resource for the research community and for others interested in hereditary deafness.

As each gene is cloned, a small piece of the puzzle is assembled in an ongoing attempt to understand cochlear function and how dysfunction can lead to deafness. Although the complexity of the hearing organ has long been appreciated, its intricacies are underscored by the great variety of functions proposed for the deafness genes that have already been cloned. The functions of these genes and how they may contribute to the hearing process are described below.

\section{Anatomy and Function of the Cochlea}

The hearing organ is an anatomically beautiful structure, consisting of many different cell types and unique elements

Table 1

Common forms of syndromic deafness

\begin{tabular}{|c|c|c|}
\hline Syndrome & Major Features (besides deafness) & Protein \\
\hline $\begin{array}{l}\text { Alport syndrome } \\
\text { X-linked (XL) } \\
\text { Autosomal recessive (AR) }\end{array}$ & Nephritis; ocular abnormalities & $\begin{array}{l}\text { Collagen type IV } \alpha 5 \text { (XL) } \\
\text { Collagen type IV } \alpha 3 \text { (AR) } \\
\text { Collagen type IV } \alpha 4 \text { (AR) }\end{array}$ \\
\hline Branchio-oto-renal syndrome & Branchial remnants; renal anomalies & EYAl \\
\hline Jervell and Lange-Nielsen syndrome (JLNS1-2) & Cardiac conduction defects & $\begin{array}{l}\text { KVLQT1 (JLNS1) } \\
\text { MinK/IsK (JLNS2) }\end{array}$ \\
\hline Neurofibromatosis type 2 & Acoustic neuromas & Merlin \\
\hline Pendred syndrome & Thyroid goiter & Pendrin \\
\hline Stickler syndrome (STLl-3) & Orofacial deformaties; ocular abnormalities; arthritis & $\begin{array}{l}\text { Collagen type II } \alpha \text { l (STL1) } \\
\text { Collagen type XI } \alpha 2 \text { (STL2) } \\
\text { Collagen type XI } \alpha 1 \text { (STL3) }\end{array}$ \\
\hline Usher syndrome (USH1A-F, USH2A-C, USH3) & Retinitis pigmentosa & $\begin{array}{l}\text { Myosin VIIa (USH1B) } \\
\text { Usherin (USH2A) }\end{array}$ \\
\hline Waardenburg syndrome (WS type I-IV) & Pigmentary abnormalities & $\begin{array}{l}\text { PAX3 (WS type I/II) } \\
\text { MITF (WS type II) } \\
\text { Endothelin-B, endothelin-B receptor, } \\
\text { SOX10 (WS type IV) }\end{array}$ \\
\hline
\end{tabular}


acting in concert to deliver a symphony of sound. Unfortunately, the delicate nature of the organ, its small size, and the fact that it is embedded in the hardest bone in the body, the temporal bone, make studying this tissue especially difficult. Despite this, great advances have been made in understanding the mechanical and sensorineural processes of hearing.

Hearing begins as sound waves are captured by the auricle, travel through the external auditory canal, and hit the tympanic membrane (Fig. 1). Vibration of this thin membrane causes movement of the auditory ossicles, the three bones of the middle ear, which convey the acoustic stimulus to the fluidfilled inner ear. The stapes, the last bone in this series, presses against the oval window, a membrane covering one of the fluid-filled ducts of the cochlea. When the stapes moves, a pressure wave is created, which travels down the upper cochlear duct (scala vestibuli). Increased pressure pushes on the basilar membrane that stretches the length of the cochlear duct, causing it to vibrate with each cycle of the sound. The basilar membrane varies in its width and thickness causing different regions to move at different sound wave frequencies. As a result, only the hair cells located over the particular portion of resonating basilar membrane will be stimulated in response to a given frequency of sound wave (Fig. 2). In fact, this membrane represents a continuum, with high frequencies detected at its base and low frequencies detected at its apex.

When the basilar membrane moves, it causes movement of both the inner and outer hair cells, which lie on top of this membrane. On the apical surface of the hair cells are stereocilia, which project upwards and are embedded in the tectorial membrane (Fig. 2). The relative movement of the basilar mem- brane and tectorial membrane causes deflection of these stereocilia, which in turn opens mechanically-gated ion channels. This allows potassium ions $\left(\mathrm{K}^{+}\right)$in the endolymph (a unique extracellular fluid bathing the hair cells and containing atypically high concentrations of $\mathrm{K}^{+}$), to pass into the hair cell and depolarize it. This stimulation is then relayed to the brain via neurons that synapse with the hair cells.

\section{FUNCTIONAL ROLE OF DEAFNESS GENES}

With this basic understanding of the mechanics of hearing described above, the functional roles played by the various genes implicated in hearing loss can be interpreted. The largest group of genes responsible for nonsyndromic deafness encodes ion channels and gap junctions. Gap junctions create large nonselective pores between cells, allowing intercellular communication of many small molecules, whereas ion channels are relatively selective for the subset of ions that can pass through them. The $K C N Q 4$ gene encodes a $\mathrm{K}^{+}$channel, which is thought to allow efflux of $\mathrm{K}^{+}$that has excited the hair cells during acoustic stimulation. ${ }^{6}$ Three other genes known to encode the gap junction proteins connexin 26 , connexin 30 , and connexin 31 (GJB2, ${ }^{7}$ GJB3, ${ }^{8}$ and $G J B 6^{9}$ ), are likely involved in the passive diffusion and recycling of the $\mathrm{K}^{+}$from the hair cells to the stria vascularis, a structure important in endolymph production (Fig. 2). Once in this stria, other $\mathrm{K}^{+}$channels pump the $\mathrm{K}^{+}$back into the endolymph. Furthermore, the PDS gene encodes pendrin, an anion channel proposed to function in endolymphatic fluid homeostasis. ${ }^{10}$ The role of these and

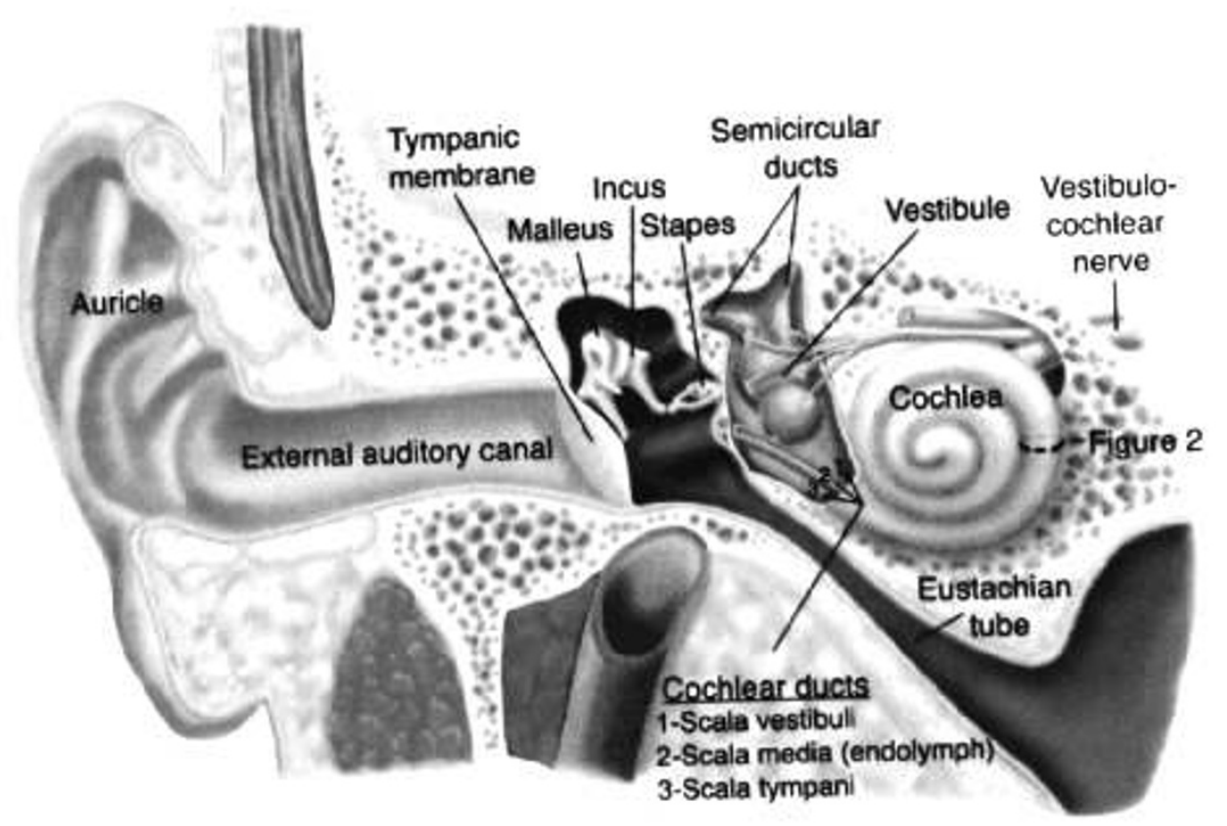

Fg. 1 Anatomical diagram of the hearing organ. Sound waves are captured by the auricle, travel through the external auditory canal, and hit the tympanic membrane causing movement of the malleus, incus, and stapes. When the stapes moves, a pressure wave is created that travels down the upper cochlear duct (scala vestibuli) and pushes on the basilar membrane causing different regions to move at different sound wave frequencies. (Adapted by Jason Lin with permission from Netter, FH. Atlas of Human Anatomy. Plate \#87. Copyright 1989 Ciba-Giegy Corporation.) 


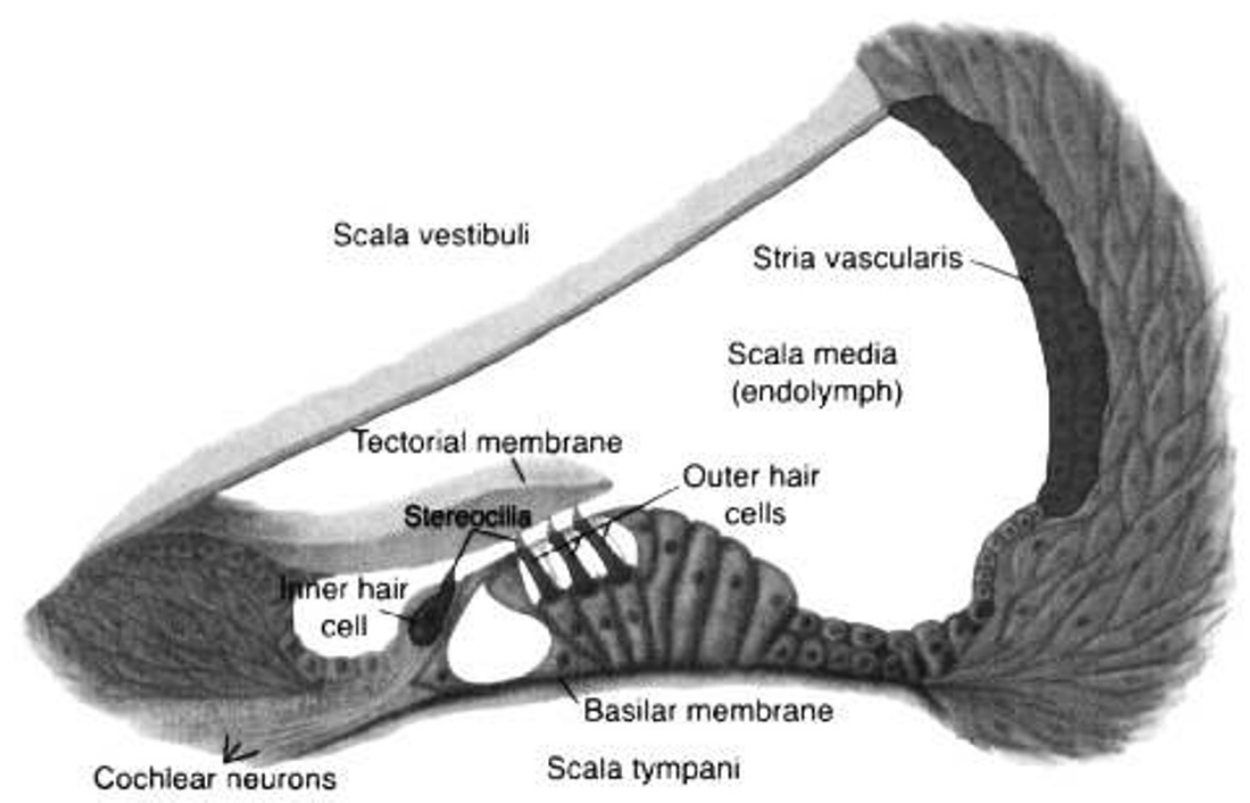

Fg. 2 A cross section of the cochlea. When the basilar membrane moves, it causes movement of both the inner and outer hair cells. The relative movement of the basilar membrane and tectorial membrane causes deflection of the stereocilia, which in turn opens mechanically-gated ion channels. This allows $\mathrm{K}^{+}$in the endolymph to pass into the hair cells and depolarize them. This stimulation is then relayed to the brain via cochlear neurons that synapse with the hair cells. (Adapted with permission from Steel, KP. The benefits of recycling. Science. 285:1363-64. Copyright 1999 American Association for the Advancement of Science.)

other channels and gap junctions in hearing and deafness has recently been described in more depth. ${ }^{11,12}$

Another group of genes responsible for nonsyndromic deafness encodes cytoskeletal proteins. These proteins are thought to be important in maintaining the structure of the hair cells and their highly organized stereocilia. Two of these genes are unconventional myosins, involved in maintaining structural integrity of the stereocilia through membrane trafficking $(M Y O 7 A)^{13}$ and possibly actin organization (MYO15). ${ }^{14}$ Another gene encoding human diaphanous (DIAPH1) is thought to create a temporary scaffolding for actin during cell division. ${ }^{15}$ Relating to the membrane trafficking function of myosin VIIa, a gene encoding otoferlin (OTOF) may be involved in vesicle membrane fusion. ${ }^{16}$

Yet another group of proteins include extracellular matrix proteins. The $\alpha$-tectorin protein encoded by the TECTA gene is a key component of the acellular tectorial membrane. ${ }^{17} \mathrm{An}$ other gene $(\mathrm{COCH})$ encodes cochlin, which appears to be an extracellular protein residing in the spiral ligament and spiral limbus. ${ }^{18}$ Though cochlin's function is unknown, these areas are important to the overall structure of the cochlear organ.

Two transcription factors have also been implicated in nonsyndromic deafness (POU3F4 and POU4F3). Although specific genetic targets of these transcription factors have not yet been identified, POU4F3 may be involved in directing the differentiation of hair cells ${ }^{19}$ and POU $3 F 4$ may have a role in the function of spiral ligament fibrocytes. ${ }^{20}$

Another gene implicated in nonsyndromic deafness is DFNA5. This gene lacks homology with any known proteins and no functional studies have yet been reported. ${ }^{21}$ As a result, its role in the cochlea remains to be elucidated.

Two last genes involved in nonsyndromic deafness are not nuclear encoded genes but are found in the mitochondrial genome. Mutations in these genes are passed on by maternal inheritance. Both of these genes encode RNA molecules, one a ribosomal RNA ( $12 \mathrm{~S}$ rRNA) and one a transfer RNA $\left(\mathrm{tRNA}^{\mathrm{ser}(\mathrm{UCN})}\right)$, and are involved in protein translation in the mitochondria. An excellent review of mitochondrial deafness was recently published. ${ }^{22}$

It is clear from these gene descriptions that the discovery of genes involved in deafness is critical to advancing the understanding of how the inner ear functions and how the disruption of certain genes can cause deafness. Not described above are 19 other genes that are implicated in syndromic deafness. Although these genes are not unique to the cochlea, understanding their role in this organ has also been helpful in elucidating the molecular basis of the hearing process. In addition, many deafness genes have been identified in other organisms. These studies have not only facilitated the understanding of the hearing process but in many cases they have helped identify homologous human genes, some of which have been found to result in human hereditary deafness.

\section{NONGENETIC CAUSES OF DEAFNESS}

Because a large proportion of nonsyndromic hereditary hearing loss is recessive ( $80 \%$ ), there are many instances when a couple with no history of deafness will give birth to a deaf 
child. The underlying cause of these sporadic cases can be especially difficult to determine because the hearing loss may be either genetic or acquired. It is therefore important to be aware of nongenetic causes of hearing impairment. For example, in previous decades, infectious agents such as rubella and bacterial meningitis were common causes of environmental hearing loss. Although the frequency of such infections has dropped with the introduction of vaccines, a concomitant improvement in the survival rates of preterm babies has increased the proportion of hearing loss related to stays in the neonatal intensive care unit (NICU). Thus, the overall incidence of nongenetic deafness has remained approximately unchanged.

Among graduates of the NICU, three factors, outside of infectious agents, are most commonly associated with hearing loss. The first of these is hypoxia, a condition often associated with apnea, use of ventilation, difficult delivery, low Apgar scores, or low blood oxygen level. ${ }^{23}$ In addition, hypoxia is also associated with persistent pulmonary hypertension and the use of extracorporeal membrane oxygenation (ECMO) treatment. Hypoxia is known to be associated with neurodevelopmental deficits but the exact mechanism of hypoxia-related hearing loss is unclear. This lack of understanding is in part due to the multitude of interacting factors present in NICU babies that may confound the situation.

A second factor associated with NICU-related hearing impairment is hyperbilirubinemia, often a result of rhesus incompatibility. In this situation, high levels of unconjugated bilirubin cross the immature blood-brain barrier and deposit in the gray matter causing neurotoxicity. This is thought to lead to sensorineural hearing loss, which is usually permanent, although some cases may be reversed once bilirubin levels return to normal. ${ }^{24}$

Hearing loss may also be caused by the use of ototoxic medication. Several of the suspected causes of such ototoxicity are aminoglycoside antibiotics (e.g., gentamicin, tobramycin, and amikacin) and diuretics (e.g., furosemide). There is substantial evidence that the ototoxicity of aminoglycosides is significantly increased by the presence of the A $1555 \mathrm{G}$ mutation in the mitochondrial $12 \mathrm{~S}$ rRNA gene. ${ }^{22}$ This ribosomal protein mutation is thought to make the protein look more like a bacterial ribosome, which is the natural target of these aminoglycosides.

With the advent of vaccinations, the incidence of hearing loss due to infectious agents has decreased. However, such causes are still responsible for a significant portion of acquired hearing loss. The biggest contributor in this regard is intrauterine cytomegalovirus (CMV) infection, found in approximately $1 \%$ of newborns. Only $10 \%$ of these cases develop clinical manifestations of the infection, of which $60 \%$ develop hearing loss. ${ }^{23}$ However, a significant proportion of asymptomatic $\mathrm{CMV}$ patients also develop hearing impairment leading to the overall estimation that $12 \%$ of congenital sensorineural hearing loss is due to CMV infection. ${ }^{23}$ Although the incidence of bacterial meningitis has decreased since the introduction of the $H$. influenza type B vaccine, other infectious agents (e.g., $S$. pneumoniae) have kept meningitis-related deafness from disappearing. A portion of the deafness associated with meningi- tis is thought to be secondary to the use of aminoglycoside antibiotics, but it is clear that most is due to direct damage to the cochlea. ${ }^{25}$ Congenital rubella has also become rare since vaccine development, yet hearing loss is still the most common permanent manifestation of congenital rubella, leaving it on the primary list of infectious causes of hearing impairment. One other notable congenital infection leading to hearing loss is untreated toxoplasmosis.

In addition to infections and NICU-related causes of hearing loss, there are several other etiologies including otitis media, noise-induced hearing loss, and head trauma. Otitis media is the most common cause of acquired childhood hearing loss and typically results in temporary conductive loss, although permanent sensorineural loss may sometimes occur. ${ }^{26}$ The most common features associated with otitis media are infection, inflammation, and/or fluid in the middle ear. Noise-induced deafness and hearing impairment associated with head trauma can occur at any age; however, noise-induced loss is usually irreversible, whereas recovery from hearing loss due to head trauma may be possible. ${ }^{23}$

As this brief look at the nongenetic causes of deafness suggests, the signs that hearing loss is acquired, and not genetic, are not always obvious. However, recognition of these signs is critical, for in many cases there are interventions that can either prevent the hearing loss or stop its progression. Unfortunately, diagnosis of hearing loss remains difficult even when environmental causes have been ruled out, because the current paucity of molecular diagnostic tests makes it difficult to positively conclude that a patient's deafness has genetic origins. It is hoped that as molecular genetic diagnosis improves, such assessments will become easier.

\section{UNIVERSAL NEWBORN HEARING SCREENING}

Newborn hearing screening has been available for some time, but previously performed only on newborns at high risk. ${ }^{27}$ These high risk indicators were generated by the Joint Committee on Infant Hearing and their most recent list appears in Table $2 .{ }^{28}$ Unfortunately, it was discovered that only one-half of the children with hearing loss were being detected when only those in high risk registries were screened. ${ }^{29}$ This meant that hearing impairment was going undetected in many children until it was noticed by parents or teachers, usually around 2.5 years of age. ${ }^{30}$ However, it is well known that early detection of hearing impairment is critical to the development of language. ${ }^{31}$ This is not only true for achieving communication skills but also for reaching other cognitive stages of development, because learning is often dependent on the attainment of language. For this reason many states are passing laws mandating that all newborns be screened for hearing loss.

Facilitating this legislative process is the existence of two different automated tests for assessing hearing function in newborns. One test assesses auditory brainstem responses (ABR) by measuring electroencephalographic waves detected using three electrodes on the infant's scalp. These waves are normally generated by the cochlea in response to a sound stim- 
Table 2

Indicators associated with sensorineural and/or conductive hearing loss

1. Family history of hereditary childhood sensorineural hearing loss

2. In utero infection (CMV, rubella, toxoplasmosis, syphilis, herpes)

3. Craniofacial anomalies

4. Birth weight less than $1500 \mathrm{~g}$

5. Hyperbilirubinemia at a serum level requiring exchange transfusion

6. Ototoxic medications, including but not limited to the aminoglycosides, used in multiple courses or in combination with loop diuretics

7. Bacterial meningitis

8. Apgar scores of 0 to 4 at 1 minute or 0 to 6 at 5 minutes

9. Mechanical ventilation lasting 5 days or longer

10. Stigmata or other findings associated with a syndrome known to include a sensorineural and/or conductive hearing loss

ulus and sent to the brain through the cochlear nerve. A second test detects otoacoustic emissions (OAE), which are sound waves generated by the inner ear and detected using a microphone in the ear canal. It is thought that physical movement of the outer hair cells generates these emissions during the normal cochlear transduction process, thus indicating proper cochlear function. Although OAE screening is faster and easier than $\mathrm{ABR}$, the test has significant false positive rates. However, when the two tests are combined, or when a rescreen is performed, the false positive rate can decrease to less than $3 \% .{ }^{32}$ If a newborn does not pass this initial screening, the child is then referred for further evaluation by an audiologist. At this point, a more extensive diagnostic ABR test is performed, allowing assessment of a wider range of frequencies. This test may also include both air and bone conduction tests, allowing the audiologist to differentiate between conductive and sensorineural hearing losses. In addition, further OAE testing allows discrimination between sensory and neural types of hearing loss. If a hearing impairment is found, the child is referred to an otolaryngologist and appropriate habilitative services.

\section{DIAGNOSIS OF THE ETIOLOGY OF DEAFNESS}

Despite the diagnosis of hearing loss becoming relatively straightforward, an understanding of the etiology of the impairment has traditionally been very difficult, especially in young children. This is in large part due to the numerous genetic and environmental causes of deafness, many of which do not have definitive tests to aid in their diagnosis. The primary care physician is often faced with the difficult task of either ordering an exhaustive battery of tests, which may not provide further insight as to the etiology, or trying to handpick specific tests that may be indicated in a given case. Neither situation is ideal and a more expedient plan may be to refer the child to an otolaryngologist, who may also enlist the help of a team of professionals including an audiologist, a clinical geneticist, an ophthalmologist, a genetic counselor, and other specialists.
A careful family history must always be elicited to help determine if the hearing loss is genetic. Unfortunately, many genetic cases are sporadic, meaning that neither parent has hearing impairment, nor is a family history present. In these cases, possible environmental causes of deafness must be excluded prior to considering that the hearing loss may be genetic. In addition, possible syndromic forms of deafness must also be identified so that other features of the syndrome can be addressed if necessary. The clinical geneticist can be very helpful in this regard, helping to recognize subtle anomalies associated with hearing loss, allowing specific diagnosis of a syndromic form of deafness. Furthermore, because a high proportion of children with hearing loss have ocular anomalies, it is usually worthwhile to enlist the help of an ophthalmologist. This specialist can aid in diagnosing ocular defects associated with syndromic deafness (e.g., Usher or Waardenburg syndromes) or infectious agents (e.g., CMV and toxoplasmosis).

Part of the decision to perform certain diagnostic tests may be related to the yield that the test may bring. For instance, examination for a particular infectious agent, such as toxoplasmosis, may be warranted when there is a treatment for the infection, which could prevent further hearing loss and other sequelae. It may also be important to test for particular syndromic disorders if there are grave consequences when undiagnosed. For example, Jervell and Lange-Nielsen syndrome is a syndromic form of hearing loss that includes deafness and cardiac conduction defects (long QT). Unfortunately, the first sign of the cardiac defect may be sudden death. Thus, it may be highly advantageous to perform an electrocardiogram to diagnose this rare disorder so that preventative measures can be taken.

Until recently, very few molecular tests were available to aid in the diagnosis of genetic causes of deafness. This is less important when dealing with syndromic deafness, which is often accompanied by an array of defining symptoms. However, without any other guiding features, the lack of molecular tests makes diagnosis of nonsyndromic hereditary deafness particularly difficult. Fortunately, the recent explosion in the discovery of nonsyndromic deafness genes provides a number of options for confirming the diagnosis. Although 15 genes are currently on this list, with minor exception, the only gene for which screening is being performed clinically is connexin 26 (Cx26). This is because most of the other genes are relatively rare causes of deafness and many of the genes are so large that screening is very costly. However, as new screening methodologies are developed, additional genetic tests for hearing will be considered.

\section{INTERVENTION AND MANAGEMENT}

As soon as a diagnosis of hearing loss is made, an effective habilitation plan needs to be developed. Such decisions may be less complex with adult-onset deafness, in which language acquisition and other developmental issues are not of concern and the patient is capable of making decisions for him or herself. However, when dealing with a child, these decisions be- 
come much more involved. In addition to considering the patient, a plan of care should include input from a number of other parties including the otolaryngologist, the audiologist, the genetic counselor, those involved in the education of the child, and most importantly, the parents themselves. For profound deafness, a deaf couple may prefer that their child learn sign language, while a hearing couple might opt for a cochlear implant, an electronic device that can allow certain deaf children to hear a comparable sound level to their peers. ${ }^{3.3} \mathrm{De}$ pending on the level of hearing loss, other options include the use of hearing aids and other assistive learning devices. The main goal, however, is that the strategy be appropriate for the child and agreed upon and initiated as soon as possible so that the child can develop a method of communication, a critical step in reaching other developmental milestones.

\section{GENETIC COUNSELING AND ETHICAL ISSUES IN THE DEAF CULTURE}

As with any inherited genetic disorder, deafness requires the input of the trained genetic counselor. However, this particular phenotype carries many of its own unique and sensitive issues. The desire to share a common language has resulted in the development of a tightly organized Deaf culture. Even if a deaf person does not participate in this "culture," it is likely that a deaf person may choose a partner who is also deaf because they share a common language, referred to as linguistic homogamy. The choice to select a mate of similar phenotype is known as assortative mating. Unfortunately, this can sometimes lead a couple to incorrectly assume that they will have deaf children because they are both deaf. In fact, due to the enormous genetic heterogeneity discussed above, $90 \%$ of deaf by deaf matings result in hearing children. ${ }^{3}$

One difficulty for the many people who work in the field of deafness is accommodating opposing attitudes toward deafness. On one hand, the average hearing couple, when unsuspectingly presented with a deaf child, may be devastated to discover their child's "deficiency." In stark contrast, a deaf couple may be equally devastated to learn that their child can hear. These differing perspectives are rooted not only in the desire to communicate most effectively with one's child, but also in the more global attitude of what traits are "normal" or "desirable." The definitions of these words clearly lie in the subjective opinions of their users.

The conviction that deafness is simply another way of life runs strongly within the Deaf community. As a result of this perspective, many supporters of the Deaf culture are opposed to the use of genetic testing for deafness, feeling that it stigmatizes their deafness as a "disease." In addition, many are opposed to the use of cochlear implantation, believing that it could eradicate their culture through the elimination of hearing loss. Although these views should be respected, they are, at least in part, unfounded. For instance, although genetic testing is often used in clinical diagnostics, the "disease" categorization is primarily associated with societal views of "the norm." Furthermore, as the field of genetics expands, it is quickly be- coming possible to "test" for characteristics that are traditionally viewed as "normal" variants. It is unlikely that the ability to test for such variation will cause certain differences to carry the stigma of "disease."

As for the eradication of the deaf culture by cochlear implantation, it must be noted that implantation is not an appropriate treatment for all deafness. It relies on the presence of a welldeveloped cochlear structure that can be augmented by the implanted device. Many individuals with profound deafness do not have such a scaffold and are therefore inappropriate candidates for implantation.

\section{SUMMARY}

Recent advancements have been made in understanding, diagnosing, and treating deafness. In particular, much has been learned from the discovery of a small fraction of the genes responsible for deafness. This understanding will doubtless increase as additional genes are cloned and their functions elucidated. Trailing close behind these achievements will be more clinical advancements facilitating diagnosis of the etiologies of deafness. Integrating these genetic and clinical perspectives is critical to the development of better treatments and interventional strategies for deafness and its associated difficulties. Although opinions toward these advancements are likely to vary between the hearing population and the Deaf community, a growing understanding of the hearing process and how genetic variations result in deafness is ultimately likely to offer benefits to both groups.

\section{Acknowledgments}

The authors thank several colleagues of the Harvard Center for Hereditary Hearing Loss for their helpful comments on the manuscript, Mr. Stefan Waversik for his editing of the manuscript, and Jason Lin for his artwork on Figure 1.

\section{References}

1. Denoyelle F, Marlin S, Weil D. Moatti L, Chauvin P, Garatedian EN, Petit C. Clinical features of the prevalent form of childhood deafness, DFNB1, due to a connexin-26 gene defect: Implications for genetic counselling. Laniet 1999:353:12981303.

2. Cohn FS, Kelley PM, Fowler TW'. Gorga MP. Lefkowitz DM, Kuehn HJ. Schaefer GB, Gotar LS, Hahn FI. Harris DI, Kimberling WT. Clinical studies of families with hearing loss attributable to mutations in the connexin 26 gene (GIB2/DFNB 3 . Pediatr 1994;103:540-550.

3. Gorlin RT. Toriello HV. Cohen MMI. Hereditary hearing loss and its syndromes. Oxford: Oxford University Press, 1995

4. Morton NF. Genetic epidemiology of hearing impairment. Ann N Y Acad Sci 1991; $630: 16-31$.

5. Van Camp G, Smith RJH. Hereditary Hearing Loss Homepage, $1999 \mathrm{http}: / /$ dnalabwww.uia.ac.he/dnalab/hhh

6. Kubisch C, Schroeder BC, Friedrich T, Lutjohann B. E.-Amraoui A, Marlin S. Petit C. lentsch TI. $\mathrm{KCNQ} 4$, a novel potassium channel expressed in sensory outer hair cells, is mutated in dominant deafness. Cell 1999:96:437-446.

7. Kelsell DP, Dunlop I. Stevens HP, Lench NI, Liang IN, Parry G, Mueller RF, Leigh IM. Connexin 26 mutations in hereditary non-syndromic sensorineural deafness. Nature 1997;387:80-83.

8. Xia IH, Liu CY, Tang BS, Pan Q, Huang L, Dai HP. Zhang BR, Xie W, Hu DX, Zheng $D$, Shi XL, Wang DA, Xia K, Yu KP, Liao XD, Feng Y, Yang YF, Xiao JY, Xie DH Huang IZ. Mutations in the gene encoding gap junction protein beta-3 associated with autosomal dominant hearing impairment. Nat Genet 1998;20:370-373.

9. Grifa A, Wagner CA. D'Ambrosio L, Melchionda S, Bernardi F, Lopez-Bigas N, 


\section{Rehm et al}

Rabionet R, Arbone's M, Monica MD, Estivill X, Zelante L, Lang F, Gasparini P. Mutations in GJB6 causc nonsyndromic autosomal dominant deafness at DFNA3 locus. Nat Gent 1999;23:16-18.

10. Everett LA, Morsli H, Wu DK, Green ED. Expression pattern of the mouse ortholog of the Pendred's syndrome gene ( $\mathrm{Pds}$ ) suggests a key role for pendrin in the inner ear. Proc Natl Acad Sci LISA 1999:96:9727-9732.

11. Holt JR, Corcy DP. Ion channel defects in hereditary hearing loss. Ne'uron 1999;22: $217-219$.

12. Steel K.P. The benefits of recycling. Sotence 1999;285:1363-1.364.

13. Hasson T, Gillespic PG, Garcia IA, Macl onald RB, Zhao Y, Yee AG, Mooseker MS, Corey DP. Unconventional myosins in inner-ear sensory epithelia. / Cell Biol 1997; 137:1287-1307.

14. Probst FI, Fridell RA, Raphael Y, Saunders TL, Wang A, Liang Y, Morell RJ, Touchman IW, Lyons RH, Noben-Trauth K, Friedman TB, Camper SA. Correction of deafness in shaker-2 mice by an unconventional myosin in a BAC transgene. Science 1998:280:1444-1447

15. Lynch ED, Lee MK, Morrow IE, Welcsh PL, Leon PE, King MC. Nonsyndromic deafness DFNAl associated with mutation of a human homolog of the Drosophila gene diaphanous. Science 1997;278:1315-1318.

16. Yasunaga S, Grati M, Cohen-Salmon M, El-Amraoui A. Mustapha M, Salem N, El-Zir E. Loiselet 1. Petit C. A mutation in OTOF, encoding otoferlin, an FER-1-like protein, causes DFNB9, a nonsyndromic form of deafness. Nat Genet 1999;21:363369.

17. Verhoeven K, Van Laer L, Kirschhofer K, Legan PK, Hughes DC, Schatteman I, Verstreken M, Van Hauwe P, Coucke P, Chen A, Smith RI, Somers T, Offeciers FE, Van de Heyning P. Richardson GP, Wachtler F, Kimberling WJ. Willems PJ, Govaerts PJ, Van Camp G. Mutations in the human alpha-tectorin gene cause autosomal dominant non-syndromic hearing impairment. Nat Genet 1998;19:60-62.

18. Robertson NG, Lu L, Heller S, Merchant SN, Eavey RD, McKenna M, Nadol Jr. JB, Miyamoto RT, Linthicum Jr. FH, Lubianca Neto JF, Hudspeth AI, Seidman CE, Morton CC, Seidman IG. Mutations in a novel cochlear gene cause DFNA9, a human nonsyndromic deafness with vestibular dysfunction. Nat Genet 1998;20:299303

19. Vahava O, Morell R, Lynch ED, Weiss S, Kagan ME, Ahituv N, Morrow JE, Lee MK, Skvorak AB, Morton CC. Blumenfeld A, Frydman M, Friedman TB, King MC, Avraham KB. Mutation in transcription factor POU4F3 associated with inherited progressive hearing loss in humans. Science 1998;279:1950-1954.
20. Minowa O, Ikeda K, Sugitani $Y$, Oshima T, Nakai S, Katori $Y$, Suzuki M, Furukawa $M$, Kawase T, Zheng Y, Ogura M, Asada Y, Watanabe K, Yamanaka H, Gotoh S, Nishi-Takeshima M, Sugimoto T, Kikuchi T, Takasaka T, Noda T. Altered cochlear fibrocytes in a mouse model of DFN3 nonsyndromic deafness. Science 1999;285: $1408-1411$.

21. Van Laer L, Huizing EH, Verstreken M, van Zuijlen D, Wauters JG, Bossuyt PI, Van de Heyning P, McGuirt WT, Smith RJ, Willems PJ, Legan PK, Richardson GP, Van Camp G. Nonsyndromic hearing impairment is associated with a mutation in DFNA5. Nat Genet 1998;20:194-197.

22. Fischel-Ghodsian N. Mitochondrial deafness mutations reviewed. Hum Mutat 1999;13:261-270

23. Roizen NJ. Etiology of hearing loss in children: nongenetic causes. Pediatr Clin North Am 1999;46:49-64.

24. Kuriyama $\mathrm{M}$, Tomiwa $\mathrm{K}$, Konishi $\mathrm{Y}$, Mikawa $\mathrm{H}$. Improvement in auditory brainstem response of hyperbilirubinemic infants after exchange transfusions. Pediatr Neurol 1986;2:127-132.

25. Francois M, Laccourreye L, Huy ET, Narcy P. Hearing impairment in infants after meningitis: Detection by transient evoked otoacoustic emissions. J Pediatr 1997;130: 712-717.

26. Karver SB. Otitis media. Primary Care 1998;25:619-632.

27. Mencher GT. Early Identification of Hearing Loss. Basel: Karger, 1976

28. Joint Committee on Infant Hearing. Position Statement. Pediatr 1995;1994:95:152156

29. Mauk GW, White KR, Mortensen LB, Behrens TR. The effectiveness of screening programs based on high-risk characteristics in early identification of hearing impairment. Ear Hear 1991;12:312-319.

30. Gravel IS, Tocci LL. Setting the stage for universal hearing screening. New York: Thieme, 1998

31. Yoshinaga-Itano C, Sedey AL, Coulter DK, Mehl AL. Language of early- and lateridentified children with hearing loss. Pediatr 1998;102:1161-1171.

32. Erenberg A, Lemons J, Sia C, Trunkel D, Ziring P. Newborn and infant hearing loss: Detection and intervention. American Academy of Pediatrics Task Force on Newborn and Infant Hearing, 1998-1999. Pediatr 1999;103:527-530.

33. Francis HW, Koch ME, Wyatt JR, Niparko JK. Trends in educational placement and cost-benefit considerations in children with cochlear implants. Arch Otolaryngol Head Neck Surg 1999:125:499-505. 